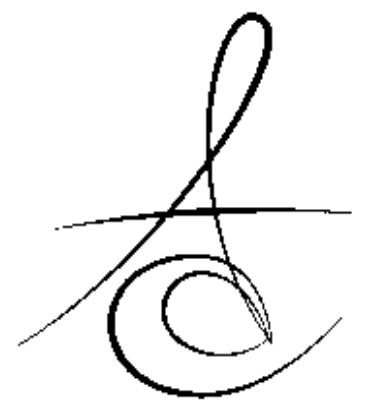

\title{
ENDODONTİK TEDAVİLİ DİŞLERİN RESTORASYONUNDA POST MATERYALLERI
}

POST MATERIALS IN RESTORATION OF ENDODONTICALLY TREATED TEETH

Yrd. Doç.Dr. Fuat AHMETOĞLU*

Dt. Güler YILDIRIM **
Yrd. Doç.Dr. Neslihan ŞİMŞEK*

Prof.Dr. N. Tülin POLAT**

Makale Kodu/Article code: 1216

Makale Gönderilme tarihi: 22.06.2013

Kabul Tarihi: 04.10 .2013

\section{ÖZET}

Endodontik postlar restoratif sistemin bir parçası olduğundan, restorasyonun başarısı veya başarısızlığı postların bilinmesiyle yakın ilişkidedir. Endodontik postlar geçmişten günümüze farklı materyallerden ve farklı şekillerde üretilmiştir. $\mathrm{Bu}$ değişken post sistemlerinin birbirlerine göre avantaj ve dezavantajları bulunmaktadır. Bu makale endodontik tedavisi yapılmış bir dişe uygulanacak olan restoratif başarının güvenliği için endodontik post sistemleriyle ilgili bilgi sunmaktadır.

Anahtar kelimeler: Endodontik postlar

\section{ABSTRACT}

Knowledge of posts is associated with the success or failures of the restoration because of endodontic posts are part of the restorative system. Endodontic posts are manufactured in different ways and different materials from past to present. These variable post systems have advantages and disadvantages to each other. This article provides information about endodontic post systems for safety of restoration of endodontically treated teeth.

Keywords: Endodontic posts

\section{GİRİ̧}

Endodontik tedavi yapılmış bir dişin restoratif ve protetik tedavisi, kalan sağlıklı dokulara uygulanan post-kor restorasyonunun prognozuna, restorasyonun genel olarak yapısal ve estetik kalitesiyle klinik adaptasyonuna bağlıdır. ${ }^{1,2}$ Endodontik tedavi sonrasında diş üzerinde doku kaybıyla beraber dental yapıda zayıflama, fiziksel ve mekanik yapıda değişiklik, mine ve dentinin renginde farklılaşma gibi sonuçlar görülebilir. Özellikle çürükle ilgili olarak pulpada meydana gelen değişiklikler sonucunda kan akımında azalma, kollajen fibrillerin dejenerasyonu ve dehidratasyona bağlı olarak dişte zayıflama meydana gelmektedir. ${ }^{3}$ Endodontik tedavi yapılmış bir dişin çiğneme kuvvetlerine karşı direnci \%5 oranında azalırken; oklüzal kavite preparasyonunda \%20;
MOD kavite preparasyonu yapılmış bir dişte ise bu oran \%63'lere kadar çıkabilmektedir. ${ }^{4}$ Bu değişim özellikle mandibular arkta ve ön kesicilerde daha fazla görülmektedir. Kanal tedavisi sırasında pulpa odasının tavanının kaldırılması, dişin fonksiyon esnasında daha fazla esnemesine yol açmakta ve bunun sonucu olarak da kırılma meydana gelebilmektedir. ${ }^{4} \mathrm{Bu}$ durumdaki dişlerde yapılacak olan post uygulamalarıyla, aşırı miktarda koronal yapının kaybedildiği dişlerde kor yapısı geri kazanılacaktır. ${ }^{5,6}$

Postlar; pinli kor yapımı, tutucu oluklar, yardımc kaviteler, asit ile pürüzlendirme ve bağlanma yöntemleriyle onarılamayan kuron kaybının olduğu durumlarda, periodontal desteği zayıf dişlerde kuron/kök oranının endodontik desteklerin kullanımıyla güçlenmesi gerektiği olgularda, malpoze dişin oklüzal ve aksiyal düzeltilmesinin pulpa bütünlüğünü bozduğu durumlarda, overdenture tekniklerinde ataçmanların kökler-

*İönü Üniversitesi, Diş Hekimliği Fakültesi, Endodonti Anabilim Dalı, Malatya.

**Inönü Üniversitesi, Diş Hekimliği Fakültesi, Protetik Diş Tedavisi Anabilim Dalı, Malatya. 
le retansiyonu gerektiğinde, restorasyon sonrası endododontik girişimin güçleşeceği pulpa prognozunun şüpheheli olduğu geniş defektli dişlerde restorasyonu tamamlamak ve devamlı kılmak amacıyla kullanılırlar. ${ }^{7}$ Ancak bu sistemlerin kırımaya eğilimli ince kök formu olan dişlerde, ısrarcı periapikal patoloji varlığında, yetersiz kanal dolgusu olan olgularda, oral hijyeni kötü ve motive edilemeyen hastalarda kullanılması uygun değildir. $^{8}$

Restoratif sistemin bir parçası olan endodontik postlar, tüm sistemin başarı ya da başarısızlığılla yakın ilişkidedir. Postlara ait bazı özel faktörler yapılan restorasyonun devamlılığı için kritik önem taşımaktadır.

\section{POST ÇEŞİTLERI}

Endodontik postlar, kullanılan materyallerin cinsine göre 3 farklı başlık altında sınılandırımaktadır: Metal alaşımlı postlar, fiber postlar ve seramik postlar. Aynı zamanda fiber postlar kendi içlerinde; quartz fiber, karbon quartz fiber, karbon fiber ve cam fiber postlar diye dört alt gruba ayrilırlar. Seramik postlar ise; cam seramikler, alüminyum oksit ile güçlendirilmiş seramikler, freze tekniği ile elde edilen seramikler ve zirkonyum esaslı seramikler olmak üzere dört alt grupta toplanır. ${ }^{9,10}$ Son dönemde Ribbond isimli (plazma ile güçlendirilmiş polietilen fiber) yeni bir post tanıtılmıştır. Örgü şerit olarak da adlandırılan bu materyal kompozit rezin veya akril ile birlikte kullanılmaktadır. ${ }^{11}$

\section{POST ÖZELLİKLERİ}

\section{Mekanik Özellikler}

Metal, fiber ya da seramik yapıdan oluşan postlar; dayanıklılık ve elastikiyet gibi mekanik özellikleriyle birbirlerine göre farklılklar gösterirler. Genellikle metal ve seramik postlar, fiber postlardan daha dayanıklı ve daha sert yapıdadırlar, ancak fiber postlar daha fazla elastiktirler ve bunun doğal sonucu olarak da dentin benzeri özellikler sergilerler. ${ }^{12-15}$ Metal ve seramik postlar yapısında herhangi bir esneme olmadan, gelen kuvvetlere özellikle yan kuvvetlere tam direnç gösterir. Bu durum dentinde, kuvvetin yoğunlaşıı̆ı bölgede kök çatlağı ve kırığı oluşmasına neden olmaktadır. ${ }^{16}$ Ancak fiber post sistemler, gelen kuvvetleri eşit miktarda dağıttığı için dentine benzer yapı gösterirler ve kırıma riskini en aza indirirler. ${ }^{16,17}$ Fiber postların elastiklik modülünün dentine benzer yapıda olduğunu gösteren çalışmalar mevcuttur. ${ }^{10,18}$

Post retansiyonu, postun dikey yönde yer değiştirmemek için göstermiş olduğu direnç kabiliyetini ifade etmektedir. ${ }^{10}$ Retansiyon, postun uzunluğundan, çapından ve açısından, kullanılan yapışııııı simandan ya da postun aktif veya pasif olmasından etkilenir. ${ }^{19}$ Postun rezistansı, yan ve rotasyonel kuvvelere karşı gösterilen direnci ifade etmektedir. Rezistans, kalan diş yapısından, postun uzunluğu ve sertliğinden, antirotasyon özelliklerin ve ferrulenin varlığından etkilenir. ${ }^{20}$ Post restorasyonların retansiyonunda ferrule etkisi önemli bir avantajdır. ${ }^{21}$ Ferrule, post yerleştirilecek kökün koronal kısmında 1-2 mm'lik band şeklinde oluşturulan bizotaj veya basamak kısımdır. Lateral ve rotasyonel kuvvetlere rezistansı sağlar. Sorensen ve Engelman ${ }^{22}$ yaptıkları çalışmada, $1 \mathrm{~mm}$ ferrule ile yapılan bir restorasyonun, ferrulesiz yapılan bir restorasyona göre 2 kat daha fazla dirençli olduğunu göstermiştir. Ancak kalan diş dokusuna bağlı olarak ferrule oluşturulamayabilir. Ferrule'nin sağlanamadığı bu gibi durumlarda metalik postlar, sağlanabildiği durumlarda ise fiber postlar tercih edilmelidir. ${ }^{23}$

\section{Estetik}

Post-kor restorasyonu yapılırken estetik yaklaşım göz ardı edilemeyecek özelliklerin başında gelmektedir. Eğer son restorasyon metal destekli porselen olmayacaksa, post materyali estetik sonucu etkileyebilmektedir. Estetiğin ön planda olduğu durumlarda, seramik ve bazı fiber post türleri tercih edilmelidir. Mekanik ve biyolojik olarak uyumlu özellikleri olan zirkonyum seramik postlar, renk ve yarı şeffaflık özelliği bakımından doğal dentine benzerdir ve dişlerin rengine uygun parlaklık sağlar ve dişeti kenarında oluşan gölgelenmeyi önleyebilmektedirler. ${ }^{11}$ Metal postlar hem restorasyonda hem de dişetinde gri renklenme gösterebilir. ${ }^{24}$ Karbon fiber postlar aynı şekilde koyu renklidir ve restorasyonda renk yansımasına neden olabilirler. ${ }^{10,16} \mathrm{Bu}$ nedenle estetiğin özellikle önemli olduğu ön bölge restorasyonlarda seramik ya da açık renkli fiber postlar (quartz, silikon yada cam fiber) kullanmalıdır. Açık renkli fiber postların translüsent özellik göstermeleri de bu postlara ayrı bir estetik avantaj katmaktadır. ${ }^{16}$

\section{Radyoopasite}

Post seçiminde, postun radyoopasite özelliklerine dikkat edilmelidir. Kök kanalı içerisine yerleştirilen post materyalinin pozisyonunun değerlendirilebilmesi için en az, diş ve çevre dokulardan ayırt edilebilecek kadar radyoopasite değerine sahip olması gerekmektedir. Metal ve seramik postlar radyografik filmlerde yeterli radyoopasiteye sahipken, fiber postlar aynı 
oranda başarı gösterememektedir ve radyografik değerleri değişkenlik göstermektedir. ${ }^{25,26}$ Finger ve arkadaşları, ${ }^{27}$ yaptıkları çalışmada kullanılan 7 farklı fiber post türünden 3 tanesinin radyoopasite değerlerinin kabul edilebilir olmadığını tespit etmişlerdir.

Post, yerleştirildikten sonra radyografide tespit edilebilmelidir. Eğer dentinden daha düşük radyoopasite değerine sahip bir post seçildiyse, radyoopak yapıştıııı siman tercih edilmelidir. ${ }^{26}$

\section{Sökülebilirlik}

Kök kanal tedavisinin ya da restorasyonun başarısız olduğu durumlarda, post materyalinin bulunduğu kanaldan uzaklaştırıması istenilebilir. İdeal bir post sistemi, tedavinin yenilenmesi gerektiğinde diş dokusuna ekstra zarar vermeden ortamdan uzaklaştırılabilmelidir. Metal postların ortamdan uzaklaştıııması için çevre diş dokusundan kaldırmak gerekmektedir. Bu durum kökte zayiflamaya ve kırımalara neden olabilecektir. Aynı durum seramik postlar içinde söz konusudur. Son dönemde madde kaybı oluşturmadan ultrasonik aletlerle metal postların güvenle kaldırılabildiği iddia edilmektedir. ${ }^{28}$ Ancak Altshul ve arkadaşları $^{29}$ postları yerinden çıkarmak için ultrasonik araç kullanımının dentinde çatlaklara sebebiyet verdiğini göstermişlerdir. Diğer taraftan fiber postlarda durum daha idealdir. Bu postlar, konvansiyonel döner aletlerle ve çözücü madde de kullanılarak, kalan dentini en az etkileyerek uzaklaştırılabilir. ${ }^{30,31}$ Fiber postların üretici firmalar tarafindan set halinde sunulması ve postun uzaklaştırıması için anahtar ya da dril mevcudiyeti çok önemli bir avantajdır.

\section{Post Şekli}

Postlar; paralel, açılı ve paralel-açılı olmak üzere 3 temel farklı şekle sahiptir. ${ }^{26}$ Paralel postlar, kanal içerisine postun çapına göre set içinde bulunan hazır delicilerle oluşturulan silindirik kanallara yerleştirilir. Bu şekil postların açılı olanlara göre tutuculuğu daha iyidir ve gelen kuvvetleri post boyunca dağıttığından kök çatlakları daha az görülür. ${ }^{10,32,33}$ Ancak bu uygulama fazla madde kaldırımasını gerektirir. En büyük dezavantajı hazırlanırken ortaya çıkmaktadır ve özellikle ince duvarlı kökler için uygun değildir. ${ }^{33,34}$ Açılı postların yerleştirilebilmesi için en az seviyede dentinin uzaklaştırıması yeterli olacaktır. Bu durum avantaj olarak görülmektedir. Özellikle ince köklerde ve hassas morfolojilerde endikedir. ${ }^{10}$ Fakat açı postların en önemli dezavantajı kama etkisi oluşturmalarıdır. ${ }^{26} \mathrm{Bu}$ etki, oklüzal kuvvetlerin postun konik şekli nedeniyle kökte zamanla vertikal kırrğa sebep olması olarak tanımlanır. Gelen kuvvetlerin apikal bölgede yoğunlaşmasıyla vertikal kök kırıkları oluşturma eğilimi artar. Paralel-açılı postlar paralel bir aksa sahiptirler ve apikalde açılanarak sonlanırlar. Bu postlar, daha önce bahsedilen her iki tekniğin olumlu özelliklerini bünyesinde barındırmaktadır. Paralel kısmı tutuculuğa katkıda bulunurken, açוı kısım ise post yuvası hazırlanırken daha az dentin kaldırımasını sağlamaktadır. ${ }^{26}$

\section{Yüzey Özellikleri}

Postun yüzey özellikleri de tutuculuğu etkileyen bir faktördür. Yüzey yapıları aktif ve pasif olmaktadır. Aktif yüzeye sahip postlar kanal duvarına tutunmak için dişli yapıya sahipken, pasif postların yüzeyi düzdür ve yapıştıııc simanlarla kanal duvarına tutunurlar. ${ }^{10}$ Dişli postlar vida gibi kanal duvarına bağlanır ve tutuculukları oldukça iyidir. Aktif postlar dişte strese neden olurlar ve kök kırı̆ı̆ı riskini artııırlar. ${ }^{35,36}$ Ancak bu postlar yeterli dentin miktarının bulunduğu köklerde güvenle kullanılabilir. ${ }^{10}$ Pasif postların yüzeyleri düzdür. Bu durum tutuculuğu olumsuz yönde etkilemektedir. Üretici firmalar bu olumsuzluğun önüne geçmek için bu postların yüzeylerini pürüzlendirerek tutuculuğu arttırmayı hedeflemektedir. Ancak seramik postların yüzeylerinde asitle pürüzlendirme yapılamaz. Dolayısıyla kompozit kor materyalleri uygulandığında ciddi tutuculuk problemleri oluştururlar. ${ }^{37}$ Seramik postların kullanım tercihinde bu durum göz önünde bulundurulmalıdır.

\section{Uzunluk ve Çap}

Postun uzunluğu, retansiyon ile doğrusal bir ilişkidedir; uzunluk arttıkça postun retansiyonu da artmaktadır. ${ }^{38,39}$ Post uzunluğuyla ilgili çeşitli uygulamalar tavsiye ediliyorsa da pratikte modifikasyonlara uğramaktadır. Bu çeşitlilik 6 farklı şekilde ifade edilmektedir; ${ }^{33,39}$

1. Post, kuronun insizo-servikal veya oklüzo-servikal boyuna eşit olmalı,

2. Post, kurondan uzun olmal,

3. Post, kuronun $4 / 3^{\prime}$ ü kadar olmal,

4. Post, kökün $1 / 2,2 / 3,4 / 5^{\prime} i$ kadar olmall,

5. Post, kret tepesi ile apeksin orta noktasinda sonlanmalı,

6. Post, apikal sızdırmazlığı bozmayacak kadar uzunluğa sahip olmalıdır.

Kök kanal boyunun dörtte üçü uzunluğunda yapılan post uygulamalarının sağlam bir tutuculuğa sahip olduğu belirtilmektedir. ${ }^{40}$ Günümüzde kabul

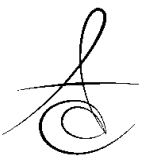


edilen en yaygın görüş, postun uzunluğu kökü perfore etmeyecek, apikal sızdırmazlığı etkilemeyecek ve en az kuron boyu kadar uzunluğa sahip olmasıdır. Genel olarak apikalde 3-5 mm guta-perka bırakılması gerektiği savunulmaktadır. Bu konuyla ilgili Mattison ve arkadaşları $^{41}$ yaptıkları çalışmada, apikalde bırakılan guta-perka miktarı ile mikro sızıntı arasındaki ilişkiyi 3 grup (7, 5 ve 3 mm'lik apikal bölge) oluşturarak değerlendirmiş ve sonuçta apikal bölgede en az 5 mm'lik guta-perka bırakılmasının gerekli olduğunu tespit etmişlerdir.

Postun çapı, kırılmaya direnç açısından önem arz etmektedir. Ancak post çapının, tutuculuğa etkisinin az olduğu yaygın olarak belirtilen görüştür. ${ }^{33}$ Başka bir ifadeyle, postun genişliginin artması aynı zamanda diş kökünün kırıma riskini de arttırmaktadır. Güncel görüş kanal preparasyonunda diş dokusunun korunması gerekliliğidir. ${ }^{42}$ Post yuvası için uygun boyutlardaki drillerle ince olandan başlanarak istenen boyuta kadar en az diş dokusu uzaklaştırılarak preparasyon yapılmalıdır.

Uzun ve dar çapa sahip postlar diş dokusunu korur ve kırılma riskini azaltır. Wu ve arkadaşları ${ }^{43}$ yaptıkları çalışmada, post boyunun çapına oranının 4.372 sınırında olması gerektiğini belirtmektedir. Bu değer çapın azalmasına bağlı olarak artarsa post-kor kuron sisteminin tutuculuğunun artacağını belirtmişlerdir.

\section{SONUÇ}

Endodontik tedavi sonrası, özellikle aşırı koronal harabiyete sahip dişlerin restorasyonunda post uygulaması tedavinin ayrılmaz bir parçası haline gelmiştir. Uygun restorasyon, kalan diş dokusunun ve kullanılan restoratif materyallerin özelliklerini bilmeyle başlamaktadır. Sunulan makalede postların çeşitli özellikleri ve bu özelliklerin restorasyona etkisinden bahsedilmektedir. Başarılı bir restorasyon, bilimsel çalışmaların sonuçlarının rehberliğinde, bireysel hasta faktörlerine ve klinikte verilen kararlara bağlıdır.

\section{KAYNAKLAR}

1. Christensen GJ. Posts and cores: state of the art. J Am Dent Assoc 1998;129:96-7.

2. Ingle $\mathrm{JE}$, Bakland LK. Endodontics. 4th ed. Lea\&Febiger, Philadelphia, 1994.

3. Rivera EM, Yamauchi M. Site comparisons of dentine collagen cross-links from extracted human teeth. Arch Oral Biol 1993;38:541-6.
4. Reeh ES, Messer HH, Douglas WH. Reduction in tooth stiffness as a result of endodontic and restorative procedures. J Endod 1989;15:512-6.

5. Robbins JW. Guidelines for the restoration of endodontically treated teeth. JAmDentAssoc 1990;120:558-62.

6. Goodacre CJ, Spolnik KJ. The prosthodontic management of endodontically treated teeth: a literature review. Part I. Success and failure data, treatment concepts. J Prosthodont 1994;3:243-50.

7. Alaçam $T$, Nalbant $L$, Alaçam A. ileri Restorasyon Teknikleri. 1. Baskı, Polat Basımevi, Ankara, 1998.

8. Rosenstiel SF, Land MF, Fujimoto J. Contemporary fixed prosthodontics. 2nd ed., The C.V. Mosby Co., St. Louis 1995.

9. Robbins JW. Restoration of the endodontically treated tooth. Dent Clin North Am 2002;46:367-84.

10. Schwartz RS, Robbins JW. Post placement and restoration of endodontically treated teeth: a literature review. J Endod 2004;30:289-301.

11. Uzun G, Keyf F. Geleneksel Post-Core Sistemlerine Bir Alternatif: Polietilen Fiber Post. Hacettepe Dişhekimliği Fakültesi Dergisi 2007;31:43-8.

12. Newman MP, Yaman P, Dennison J, Rafter M, Billy E. Fracture resistance of endodontically treated teeth restored with composite posts. J Prosthet Dent 2003;89:360-7.

13. Akkayan B, Gulmez T. Resistance to fracture of endodontically treated teeth restored with different post systems. J Prosthet Dent 2002;87:431-7.

14. Cormier $\mathrm{CJ}$, Burns DR, Moon P. In vitro comparison of the fracture resistance and failure mode of fiber, ceramic, and conventional post systems at various stages of restoration. J Prosthodont 2001;10:2636.

15. Ferrari M, Vichi A, Garcia-Godoy F. Clinical evaluation of fiber-reinforced epoxy resin posts and cast post and cores. Am J Dent 2000;13(Spec No):15B-18B.

16. Bateman G, Ricketts DN, Saunders WP. Fibrebased post systems: a review. $\mathrm{Br}$ Dent J 2003;195:43-8

17. Eskitascioglu G, Belli S, Kalkan M. Evaluation of two post core systems using two different methods (fracture strength test and a finite elemental stress analysis). J Endod 2002;28:629-33.

18. Galhano GA, Valandro LF, de Melo RM, Scotti R, Bottino MA. Evaluation of the flexural strength of 
carbon fiber-, quartz fiber-, and glass fiber-based posts. J Endod 2005;31:209-11.

19. Felton $\mathrm{DA}$, Webb $\mathrm{EL}$, Kanoy $\mathrm{BE}$, Dugoni J. Threaded endodontic dowels: effect of post design on incidence of root fracture. J Prosthet Dent 1991;65:179-87.

20. Lambjerg-Hansen H, Asmussen E. Mechanical properties of endodontic posts. J Oral Rehabil 1997;24:882-7.

21. Stankiewicz NR, Wilson PR. The ferrule effect: a literature review. Int Endod J 2002;35(7):575-581.

22. Sorensen JA, Engelman MJ. Ferrule design and fracture resistance of endodontically treated teeth. J Prosthet Dent 1990;63:529-36.

23. Zhi-Yue L, Yu-Xing Z. Effects of post-core design and ferrule on fracture resistance of endodontically treated maxillary central incisors.Prosthet Dent. 2003;89:368-73.

24. Fernandes AS, Shetty $S$, Coutinho I. Factors determining post selection: a literature review. J Prosthet Dent 2003;90:556-62.

25. Soares CJ, Mitsui FH, Neto FH, Marchi GM, Martins LR. Radiodensity evaluation of seven root post systems. Am J Dent 2005;18:57-60.

26. American Dental Association Professional Product Review. Endodontic Posts: Tips for Securing Restorative Success. 2006;1:2 (http://www.ada. org/sections/scienceAnd Research/pdfs/ 0604 tips_endoposts.pdf).

27. Finger WJ, Ahlstrand WM, Fritz UB. Radiopacity of fiber-reinforced resin posts. Am J Dent 2002; 15:81-4.

28. Abbott PV. Incidence of root fractures and methods used for post removal. Int Endod J 2002;35:63-7.

29. Altshul JH, Marshall G, Morgan LA, Baumgartner JC. Comparison of dentinal crack incidence and of post removal time resulting from post removal by ultrasonic or mechanical force. J Endod 1997; 23:683-6.

30. de Rijk WG. Removal of fiber posts from endodontically treated teeth. Am J Dent 2000; 13: 19B-21B.

31. Freedman GA. Esthetic post-and-core treatment. Dent Clin North Am 2001;45:103-16.

32. Isidor $F$, Brondum $K$. Intermittent loading of teeth with tapered, individually cast or prefabricated, parallel-sided posts. Int J Prosthodont 1992;5:25761.
33. Cheung W. A review of the management of endodontically treated teeth. Post, core and the final restoration. J Am Dent Assoc 2005;136:611-9.

34. Raiden G, Costa L, Koss S, Hernandez JL, Acenolaza V. Residual thickness of root in first maxillary premolars with post space preparation. J Endod 1999;25:502-5.

35. Burns DA, Krause WR, Douglas HB, Burns DR. Stress distribution surrounding endodontic posts. J Prosthet Dent 1990;64:412-8.

36. Standlee JP, Caputo AA. The retentive and stress distributing properties of split threaded endodontic dowels. J Prosthet Dent 1992;68:436-42.

37. Butz F, Lennon AM, Heydecke G, Strub JR. Survival rate and fracture strength of endodontically treated maxillary incisors with moderate defects restored with different post-and-core systems: an in vitro study. Int J Prosthodont 2001;14:58-64.

38. Standlee JP, Caputo AA, Hanson EC. Retention of endodontic dowels: effects of cement, dowel length, diameter, and design. J Prosthet Dent 1978;39:400-5.

39. Stockton LW. Factors affecting retention of post systems: a literature review. J Prosthet Dent 1999;81:380-5.

40. Leary JM, Aquilino SA, Svare CW. An evaluation of post length within the elastic limits of dentin. J Prosthet Dent 1987;57:277-81.

41. Mattison GD, Delivanis PD, Thacker RW, Jr., Hassell KJ. Effect of post preparation on the apical seal. J Prosthet Dent 1984;51:785-9.

42. Pilo $R$, Tamse A. Residual dentin thickness in mandibular premolars prepared with gates glidden and ParaPost drills. J Prosthet Dent 2000;83:61723.

43. Wu XH, Chen XM, Yang Y, Niu L, Yao W. [Effects of post diameter on retention of post-core crown system]. Hua Xi Kou Qiang Yi Xue Za Zhi 2005;23:220-2.

\section{Yazışma Adresi}

Yrd. Doç.Dr. Fuat AHMETOĞLU

İnönü Üniversitesi

Diş Hekimliği Fakültesi

Endodonti Anabilim Dalı,

Malatya.

e-mail: ahmetoglu.fuat@gmail.com 